\title{
ROTULAGEM DE SUPLEMENTOS ALIMENTARES DO TIPO WHEY PROTEIN: ANÁLISE DE CONFORMIDADE DE ACORDO COM AS LEGISLAÇÕES BRASILEIRAS
}

\author{
Ana Carolina Azevedo Salem ${ }^{1}$, Daniele Almeida Hernandes ${ }^{2}$, Fernanda Caroline \\ Vieira Nogueira ${ }^{3}$, Ariana Ferrari ${ }^{4}$, Daniele Fernanda Felipe ${ }^{5}$ \\ ${ }^{1}$ Mestranda do Programa de Pós-graduação em Promoção da Saúde da Universidade \\ Cesumar - UNICESUMAR, Maringá-PR, Brasil \\ ${ }^{2}$ Acadêmica do curso de Nutrição na Universidade Cesumar - UNICESUMAR, Maringá-PR, \\ Brasil \\ ${ }^{3}$ Acadêmica do curso de Farmácia na Universidade Cesumar - UNICESUMAR, Maringá- \\ PR, Brasil \\ ${ }^{4}$ Docente do Programa de Pós-graduação em Tecnologias Limpas da Universidade \\ Cesumar - UNICESUMAR, Maringá-PR, Brasil \\ ${ }^{5}$ Docente do Programa de Pós-graduação em Promoção da Saúde da Universidade \\ Cesumar - UNICESUMAR, Maringá-PR, Brasil \\ E-mail: daniele.felipe@unicesumar.edu.br
}

\section{Recebido em: 15/11/2021 - Aprovado em: 15/12/2021 - Publicado em: 30/12/2021 DOI: 10.18677/EnciBio_2021D45}

\section{RESUMO}

Os suplementos alimentares proteicos denominados whey protein vêm sendo utilizados por um crescente número de pessoas. As informações presentes nos rótulos desses produtos contribuem para a orientação do consumidor sobre o uso adequado. Sabe-se que não conformidades em rótulos podem afetar negativamente a saúde dos indivíduos. O presente estudo teve como objetivo analisar a conformidade com as legislações vigentes dos rótulos de suplementos alimentares do tipo whey protein, comercializados em Maringá-PR. Foi avaliado o grau de conformidade das informações contidas nas rotulagens de vinte suplementos alimentares do tipo whey protein, de marcas nacionais e importadas, comercializados em estabelecimentos especializados. A conformidade dos rótulos dos suplementos proteicos foi avaliada por meio do preenchimento de um checklist, elaborado baseando-se nas seguintes legislações da Agência Nacional de Vigilância Sanitária (ANVISA) que regulamentam a rotulagem dos alimentos: RDC № 243/2018; Instrução Normativa - IN no 28/2018, RDC № 259/2002, RDC № 429/2020; Lei № 10.674/2003; RDC № 26/2015. Os resultados obtidos mostraram que todas as marcas possuem inconformidades nos rótulos. É imprescindível a avaliação de rotulagem usando como base as legislações vigentes para aferição das informações, sendo que determinados produtos estavam ausentes de dados necessários para visualização do consumidor, ressaltando que $40 \%$ das marcas analisadas estavam divergentes segundo a legislação brasileira vigente. Portanto, isso mostra a necessidade de ações por parte dos órgãos reguladores, com 
fiscalização contínua e rigorosa dos rótulos de suplementos proteicos, a fim de assegurar a orientação adequada do consumidor na aquisição de produtos.

PALAVRAS-CHAVE: suplementos nutricionais, rótulo, legislação.

LABELING OF FOOD SUPPLEMENTS OF THE WHEY PROTEIN TYPE: ANALYSIS OF COMPLIANCE IN ACCORDANCE WITH BRAZILIAN LEGISLATION

\begin{abstract}
Protein food supplements called whey protein are being used by an increasing number of people. The information present on the labels of these products contributes to the consumer's guidance on the proper use. On the other hand, it is known that non-compliances in labels can negatively affect the health of individuals. The present study aimed to analyze compliance with current legislation on the labels of whey protein food supplements, sold in Maringá-PR. The degree of compliance of the information contained in the labels of twenty whey protein food supplements, of national and imported brands, sold in specialized establishments will be evaluated. The compliance of protein supplement labels will be assessed by completing a checklist, which will be prepared based on the following legislation of the National Health Surveillance Agency (ANVISA) that regulates food labeling: RDC No. 243/2018; Normative Instruction - IN No. 28/2018, RDC No. 259/2002, RDC No. 429/2020; Law No. 10674/2003; RDC No. 26/2015. Data collection will be carried out at the establishment by completing the checklist and carrying out photographic records of the labels. The collected data were tabulated in Microsoft Excel@ program, and analyzed through the percentage of the level of compliance, being expressed in table form. From the results obtained, 20 labels of different brands of whey protein were evaluated, which showed that all brands have nonconformities on the labels. Thus, considering the essential need for labeling evaluation using as a basis the current legislation to check the information, with certain products lacking the necessary data for consumer visualization, noting that $40 \%$ of the analyzed brands were divergent according to the current Brazilian legislation. Therefore, this shows the need for actions on the part of regulatory agencies, with continuous and rigorous inspection of protein supplement labels, in order to ensure adequate consumer guidance in the purchase of products.
\end{abstract}

KEYWORDS: nutritional supplements, label, legislation.

\title{
INTRODUÇÃO
}

Atualmente, o consumo de suplementos alimentares do tipo whey protein tem aumentado e, para atender estas demandas, as indústrias aumentaram o desenvolvimento de produtos contendo tal componente (TREVIZAN et al., 2019). Whey protein são proteínas extraídas da parte aquosa (soro) gerada durante o processo de fabricação do queijo (FISCHBORN, 2009). O soro pode ser processado por várias técnicas de separação de proteínas, buscando obter um concentrado, whey protein concentrado, ou um isolado, whey protein isolado, e existe também o whey protein hidrolisado (SOUZA et al., 2015; LOCKWOOD et al., 2017).

Segundo Terada et al., (2009), o principal aminoácido da proteína do soro do leite é a L-leucina, o que torna muito favorável o anabolismo muscular. Além disso, possui também um teor elevadíssimo de cálcio, além de peptídeos bioativos, o que leva a efeitos na síntese proteica do tecido muscular esquelético, contribuindo com a diminuição da gordura corporal, na modulação da adiposidade o que 
consequentemente potencializa o uso na prática da atividade física. Segundo Haraguchi, Abreu e Paula (2006), o whey protein, além de possuir valor nutricional elevado possui também um alto teor de aminoácidos essenciais e de cadeia ramificada. Portanto, ele produz o aumento na síntese proteica e diminuição da gordura corporal, o que leva principalmente os jovens a procura por esse tipo de suplementação, além de atletas que buscam através de uma ingestão exagerada de proteínas o pretexto para potencializar o ganho de massa muscular.

Várias pesquisas realizadas com o intuito de averiguar os suplementos alimentares mais consumidos entre os indivíduos, mostram que o whey protein é o mais consumido (ANDRADE et al., 2012; SILVA et al., 2018; SOARES et al., 2019). Praticantes de atividades físicas, atletas e até indivíduos com patologias buscam o whey protein como fonte nutricional, já que este possui alto valor nutricional, podendo auxiliar no anabolismo muscular, coadjuvante no controle de perda de massa óssea, regulação da saciedade, redução da gordura corporal, melhora do desempenho físico, além de seus efeitos anti-hipertensivos, e hipocolesterolêmico, reguladores da função imune (KRUGER et al., 2005; FRESTEDT et al., 2008; LUHOVYY et al., 2007).

Segundo Haraguchi, Abreu e De Paula (2006), os benefícios das proteínas do soro do leite sobre o ganho de massa muscular estão relacionados ao perfil de aminoácidos, principalmente da leucina (um importante desencadeador da síntese proteica), à rápida absorção intestinal de seus aminoácidos e peptídeos e a sua ação sobre a liberação de hormônios anabólicos, como a insulina.

Para Sgarbieri (2004), as proteínas de soro apresentam elevadas concentrações dos aminoácidos triptofano, cisteína, leucina, isoleucina e lisina, em excesso às recomendações diárias. Neste sentido, é essencial o acompanhamento de um profissional habilitado para consumir esse tipo de suplementação. Porém, não é isso que acontece, sendo que no Brasil vem ocorrendo uso indiscriminado de suplementação de whey protein (MACEDO et al., 2020).

Quanto aos malefícios de uma suplementação sem orientação, o excesso de proteínas pode ser prejudicial ao fígado e rins, podendo ser capazes de sobrecarregar tais órgãos, devido à metabolização de aminoácidos e a excreção ocorrerem nestes órgãos, respectivamente (ALVES et al., 2012). Sabendo que a dieta ocidental, usualmente, possui alta ingesta proteica e sua necessidade de suplementação não é comum, o seu excesso pode causar o aumento da produção de ureia, cólica abdominal, alterações gastrointestinais (diarreia) e aumentar o risco de desidratação), além de casos de litíase renal (CORREARD, et al., 2017; MACEDO et al., 2020). Ainda segundo Alves e Lima (2009), o consumo adicional de suplementos proteicos acima das necessidades diárias recomendadas, não gera nenhum ganho de massa muscular adicional, nem aumento do desempenho, apenas prejuízo à saúde.

A Resolução RDC no 243, de 26 de julho de 2018 (BRASIL, 2018a) dispõe sobre os requisitos para composição, qualidade, segurança e rotulagem dos suplementos alimentares e para atualização das listas de nutrientes, substâncias bioativas, enzimas e probióticos, de limites de uso, de alegações e de rotulagem complementar destes produtos. Além disso, outras normas importantes referentes à rotulagem de alimentos no Brasil são a Resolução RDC no 259/02, que trata do regulamento técnico sobre a rotulagem de alimentos embalados (BRASIL, 2002), e a RDC $n^{\circ}$ 429/20, que, por sua vez, institui os nutrientes a ser obrigatoriamente declarados na rotulagem nutricional (BRASIL, 2020). Tem-se também a Resolução RDC $n^{\circ}$ 26, de julho de 2015, que estabelece os requisitos para rotulagem 
obrigatória dos principais alimentos que causam alergias alimentares (BRASIL, 2015).

No entanto, apesar destas legislações para regulamentação, estudos recentes revelam divergências entre o que é preconizado pela Anvisa e as informações contidas nas rotulagens de suplementos proteicos comercializados em diferentes regiões do Brasil, inadequações estas que comprometem o consumo consciente e seguro do produto (MOREIRA, et al., 2013; FREITAS et al. 2015; SILVA et al., 2016; RODRIGUES et al., 2017; NASCIMENTO et al., 2019).

Estudo realizado por Silva e Souza (2016), quanto à avaliação da rotulagem de suplementos proteicos, evidenciou que todas as amostras analisadas apresentaram alguma irregularidade frente à legislação. Isto ressalta a necessidade da fiscalização contínua e rigorosa dos rótulos de suplementos proteicos, de forma a garantir que os consumidores tenham acesso a informações fidedignas sobre os suplementos proteicos. Vale ressaltar a falta de padronização nas orientações de uso descritas pelos fabricantes, visto que algumas delas poderiam induzir os usuários a um consumo de proteínas superior a dose diária recomendada.

Diante do exposto, torna-se importante o presente estudo, uma vez que é relevante avaliar a adequação das informações contidas nas rotulagens de suplementos alimentares proteicos, frente à legislação brasileira vigente, a fim de verificar se os consumidores estão tendo informações verdadeiras dos suplementos. Desta forma, a presente pesquisa teve como objetivo analisar a conformidade com as legislações vigentes dos rótulos de suplementos alimentares do tipo whey protein, comercializados em Maringá-PR.

\section{MATERIAL E MÉTODOS}

O presente estudo é do tipo transversal-descritivo, e foi realizado em estabelecimentos especializados em suplementos alimentares localizados no município de Maringá, Paraná. Foi avaliado o grau de conformidade das informações contidas nas rotulagens de vinte suplementos alimentares do tipo whey protein, de marcas nacionais e importadas. Foi solicitado ao estabelecimento permissão para a análise dos rótulos dos produtos, explicando o objetivo da pesquisa. Durante a realização da pesquisa, as amostras foram identificadas somente por códigos aleatórios, mantendo o anonimato das marcas das mesmas.

A conformidade dos rótulos dos suplementos proteicos foi avaliada por meio do preenchimento de um checklist, e elaborado baseando-se nas seguintes legislações da Agência Nacional de Vigilância Sanitária (ANVISA) que regulamentam a rotulagem dos alimentos:

- RDC № 243, de 26 de julho de 2018, dispõe sobre os requisitos para composição, qualidade, segurança e rotulagem dos suplementos alimentares e para atualização das listas de nutrientes, substâncias bioativas, enzimas e probióticos, de limites de uso, de alegações e de rotulagem complementar destes produtos (BRASIL, 2018a); - Instrução Normativa - IN no 28, de 26 de julho de 2018, que estabelece as listas de constituintes, de limites de uso, de alegações e de rotulagem complementar dos suplementos alimentares (BRASIL, 2018b);

- RDC № 259, de 20 de setembro de 2002, aprova o Regulamento Técnico sobre Rotulagem de Alimentos Embalados, e dispõe as informações obrigatórias que o rótulo deve conter (BRASIL, 2002);

- RDC № 429, de 08 de outubro de 2020, aprova o Regulamento Técnico sobre Rotulagem Nutricional de Alimentos Embalados, tornando obrigatória a rotulagem nutricional (BRASIL, 2020); 
- Lei № 10.674 , de 16 de Maio de 2003, obriga que os produtos alimentícios comercializados informem sobre a presença de glúten, como medida preventiva e de controle da doença celíaca; (BRASIL, 2003b);

- RDC № 26, de julho de 2015, dispõe sobre os requisitos para rotulagem obrigatória dos alimentos que causam alergias alimentares (BRASIL, 2015).

A coleta de dados foi realizada no estabelecimento através do preenchimento do checklist e realização de registros fotográficos dos rótulos. O checklist, foi preenchido com as denominações (C) para o item conforme, (NC) para o item não conforme e (NA) para o item que não se aplica. Os dados coletados foram tabulados no programa Microsoft Excel $\AA^{\circ}$, versão 2013, e analisados por meio de percentual do nível de conformidade, sendo expressos em forma de tabela.

\section{RESULTADOS E DISCUSSÃO}

As Tabelas 1, 2 e 3 demonstram a adequação detalhada de cada item dos rótulos analisados das 20 amostras do suplemento whey protein, de acordo com as legislações brasileiras consultadas. A Tabela 1 demonstra a adequação dos rótulos analisados das amostras do suplemento de whey protein, de acordo com a Resolução RDC n²59/2002.

TABELA 1.Adequação dos rótulos do suplemento whey protein comercializados no município de Maringá-PR, de acordo com a Resolução RDC n²59/2002.

Segundo a RDC $n^{\circ}$ 259/2002 - Conforme
Informações Obrigatórias

\begin{tabular}{ll|l|}
\hline denominação de venda & 20 & \\
& 20 & \\
lista de ingredientes & 20 & \\
conteúdo líquido & 19 & 1 \\
identificação de origem & 20 & $\mid$ \\
$\begin{array}{l}\text { nome ou razão social e } \\
\text { endereço importador, no caso } \\
\text { de alimentos importados }\end{array}$ & \\
identificação de lote & 20 & $\mid$ \\
prazo de validade & 20 & $\mid$ \\
instruções sobre o preparo e \\
uso do alimento
\end{tabular}

Fonte: Autores (2021)

Segundo pesquisas e análises realizadas com os rótulos de suplementos alimentares, é possível afirmar que os resultados encontrados demonstram algum tipo de inadequação e irregularidade em não conformidade de acordo com as resoluções. A primeira análise foi feita considerando a RDC no 259/2002, que consiste em informações obrigatórias, no qual apenas 1 rótulo apresentou discordância nas rotulagens. A irregularidade encontrada foi na ausência da "identificação de origem", sendo uma divergência que não deveria ser encontrada, pois o consumidor tem o direito de saber de onde se originou o produto do qual fará 
uso, sendo injustificável a ausência de tal informação, já que segundo a resolução é necessário que esteja presente.

Em seguida os resultados obtidos foram relacionados aos itens necessários segundo a RDC $n^{\circ}$ 429/2020, como mostrado na Tabela 2, que consiste em proporcionar informações nutricionais sobre 0 produto. Foram encontradas divergências em média de $5 \%$ dos produtos analisados, quanto ao valor energético, carboidratos, gorduras totais, gorduras saturadas, gorduras trans, fibra alimentar, e sódio. Determinados produtos estavam ausentes de tais informações, não sendo conveniente, pois a informação nutricional é essencial em um produto de uso alimentício.

TABELA 2. Adequação dos rótulos do suplemento whey protein comercializados no município de Maringá-PR, de acordo com a Resolução RDC n 429/2020.

\begin{tabular}{|c|c|c|c|}
\hline $\begin{array}{l}\text { Segundo a RDC n } 429 / 2020- \\
\text { Informação nutricional }\end{array}$ & Conforme & Não conforme & Não se aplica \\
\hline porção (g) e em medida caseira & 20 & & \\
\hline valor energético (Kcal) ou (KJ); & 19 & 1 & \\
\hline carboidratos $(\mathrm{g})$ & 19 & 1 & \\
\hline proteínas (g); & 20 & & \\
\hline gorduras totais $(\mathrm{g})$. & 19 & 1 & \\
\hline Gorduras saturadas (g) & 19 & 1 & \\
\hline Gorduras trans $(\mathrm{g})$ & 19 & 1 & \\
\hline Fibra alimentar (g) & 19 & 1 & \\
\hline Sódio (mg) & 19 & 1 & \\
\hline
\end{tabular}

Fonte: Autores (2021)

Quanto à RDC № 243/2018, que trata sobre determinados requisitos para composição do produto, a Tabela 3 mostra que foram encontrados produtos com $75 \%$ de conformidade quanto aos itens necessários, enquanto que $15 \%$ não estavam conforme e $10 \%$ não se aplicavam. Os produtos em não conformidade obtiveram os maiores erros encontrados na ausência de apresentação na designação "suplemento alimentar" em negrito, com tamanho equivalente a 1/3 do tamanho da maior fonte utilizada na marca do produto. Além disso, tiveram inconformidades em informações relacionadas à apresentação da advertência em destaque e negrito "não exceder a recomendação diária do consumo indicada na embalagem". 
TABELA 3. Adequação dos rótulos do suplemento whey protein comercializados no município de Maringá-PR, de acordo com a Resolução RDC n 243/2018.

Segundo a RDC n²43/2018 Conforme Não conforme Não se aplica

apresentar a designação

"suplemento alimentar";

apresentar a designação

"suplemento alimentar" em caixa

alta;

apresentar a designação

"suplemento alimentar" em

negrito; apresentar a designação

"suplemento alimentar" com

tamanho mínimo equivalente $1 / 3$

(um terço) do tamanho da maior

fonte utilizada na marca do

produto;

apresentar a recomendação de

uso (quantidade e a frequência

de consumo para cada um dos

grupos populacionais indicados

no rótulo);

apresentar à advertência em

destaque e negrito "Este produto

não é um medicamento";

apresentar à advertência em

destaque e negrito "Não exceder

a recomendação diária de

consumo indicada na

embalagem"

apresentar à advertência em

destaque e negrito "Mantenha

fora do alcance de crianças";

não deve apresentar imagens ou

frase que induza a uma finalidade medicamentosa ou terapêutica;

não deve apresentar imagem ou

frase que induza o produto a

conter uma substância não

autorizada ou proibida;

não deve apresentar imagem ou

frase que induza que a

alimentação não é capaz de

fornecer os componentes

necessários a saúde a uma

substância não autorizada ou

proibida;

não deve apresentar imagem ou

frase que induza que o produto é comparável ou superior aos

alimentos convencionais.

\section{8}

17

6

9

5

13

2

3
13

11

9

12

20

20

20

20

Fonte: Autores (2021) 
De fato, são informações extremamente importantes, das quais não deveria ter sido encontradas divergências, sabendo-se da importância de que o indivíduo esteja bem informado do que está consumindo. Bem como, a advertência da impossibilidade de exceder a quantidade diária, colocando em risco a saúde do usuário, dadas todas as complicações decorrentes do uso excessivo de tais substâncias, como: a sobrecarga hepática, renal e as disfunções no metabolismo. Além de não ter benefício em relação ao anabolismo muscular pelo consumo excessivo, exercendo, inclusive, efeito contrário ao desejado, como o de ganho de peso, já que o excedente pode ser armazenado na forma de triacilgliceróis em depósitos subcutâneos de tecido adiposo (ALVES et al., 2012). Desse modo, as empresas não poderiam ausentar critérios tão importantes como esses exigidos nas resoluções.

Lisbôa et al. (2011), ao analisarem determinados rótulos de repositores energéticos comercializados em Brasília, observaram que dos dez produtos importados avaliados, nove não apresentavam a designação correta do alimento, enquanto que dos 28 produtos de marcas nacionais, nove não estavam em conformidade com a legislação. Mareth (2015) também relata que dos 60 rótulos de suplementos energéticos comercializados em Brasília, apenas 16 atenderam a este item da legislação vigente. Além disso, no rótulo de 30 suplementos, a frase estava presente, porém não estavam em destaque e negrito.

Sobre a RDC no26/2015 que descreve informações relacionadas aos alérgenos alimentares, das 20 marcas de suplemento analisadas, três apresentaram não conformidade em relação ao item informação em negrito; uma apresentou não conformidade em relação ao item informação em cor contraste com o fundo do rótulo; e uma apresentou não conformidade em relação ao item informação em altura mínima de dois $\mathrm{mm}$ e nunca inferior à altura de letra utilizada na lista de ingredientes. Apenas o item informação em caixa alta que apresentou conformidade em $100 \%$ dos produtos analisados. Desse modo, colocando em risco a saúde do consumidor, visto que as informações contrastadas a respeito dos alérgenos alimentares é de suma importância, sendo possível inferir o quão prejudicial é um indivíduo fazer uso de uma substância pela qual ele é alérgico.

Em relação a Lei no 10.674/2003, a qual está relacionada com informações de presença ou ausência de glúten, se as informações estão em destaque, nítidas, e de fácil leitura, $95 \%$ dos produtos estavam em conformidade, enquanto $5 \%$ apresentaram inconformidade nas suas informações de rotulagem. Foi encontrado divergências em todos os itens. Dos 20 produtos analisados, em cada um dos itens havia um dos produtos não estavam em conformidade. Pode-se afirmar que é imprescindível informações simples, e destacadas para que todo tipo de consumidor possa ter facilidade de observar, e analisar se o produto se encaixa em sua rotina, sabendo que há uma parte populacional que é sensível à ingestão de alimentos com glúten. Dessa maneira podemos fazer uma relação com as divergências encontradas nos suplementos segundo a RDC 10.674/2003.

Segundo o estudo realizado por Silva et al., (2016) em Belém do Pará, também foram observadas informações irregulares nos produtos analisados, os quais tinham informações não legíveis, conservação, presença e ausência de glúten, imagens proibidas e prazo de validade. A ausência de determinadas informações, assim como informações incompletas e de difícil visualização são prejudiciais, e preocupantes, já que é dever da própria empresa estabelecer e seguir as legislações como são descritas, preservando a saúde do consumidor em primeiro lugar. 
No estudo realizado por Moreira et al., (2013), foi realizada uma avaliação na rotulagem de 28 suplementos alimentares comercializados no mercado varejista na região de Leopoldina-RJ, e também verificaram um alto índice $(78,6 \%)$ de irregularidades não condizentes com critérios exigidos de rotulagem obrigatórios a todos os tipos de suplementos alimentares para atletas, de acordo com a legislação vigente (BRASIL, 2010). Nuernberg et al., (2018), confirmam que o modo de apresentação dos dados na rotulagem de forma irregular contribui para induzir o consumidor na escolha do produto e evidencia a falta de fiscalização e aplicação das normas segundo a ANVISA e o Código de Defesa do Consumidor na comercialização dos suplementos alimentares.

Além disso, presume-se que a falta de literacia nutricional e em saúde, contribui ainda mais para que os usuários estejam susceptíveis a esses riscos à saúde. Principalmente, levando-se em conta o alto índice de auto prescrição ou orientação por parte de profissionais não habilitados para tal. Como demonstra o estudo realizado por Frade et al., (2016), em que a maior parte dos entrevistados frequentadores de uma academia consomem o whey protein $(32,5 \%)$ e $71,1 \%$ não são orientados por profissionais habilitados. Sendo que, $28,9 \%$ realizam a autoprescrição, $18,4 \%$ são orientados por amigos, $7,9 \%$ por professores da academia, 2,6\% pelo vendedor do produto e 0,9\% pelo fisioterapeuta.

Como pode-se observar, vários estudos demonstram irregularidades encontradas nas informações presentes nos rótulos de suplementos alimentares de acordo com as legislações vigentes. É de conhecimento científico sobre os benefícios do consumo de proteínas e suplementos alimentares de forma equilibrada e com acompanhamento nutricional. Porém, a falta de informação ou a não conformidade nos rótulos dos alimentos, principalmente desses suplementos alimentares, não permitem que o indivíduo faça uma escolha informada e ainda oferece riscos à saúde, visto que a omissão de algumas informações não permite analisar as substâncias que realmente compõem tais produtos.

É importante ações que promovam a literacia em saúde (CORNISH; MORAES, 2015), visto que, a compreensão da leitura das informações contidas no rótulo e as escolhas alimentares são influenciadas diretamente pelo conhecimento nutricional permitindo que os indivíduos façam melhores escolhas, conscientes e mais bem informadas a respeito dos seus hábitos alimentares e impactando diretamente em sua saúde e qualidade de vida.

\section{CONCLUSÃO}

Diante dos resultados obtidos na pesquisa, podemos concluir que é alta a incidência de irregularidades na rotulagem de suplementos proteicos, frente às legislações, considerando as amostras de whey protein analisadas. Isso mostra a necessidade de ações por parte dos órgãos reguladores, com fiscalização contínua e rigorosa dos rótulos de suplementos proteicos, bem como da responsabilização das empresas produtoras ou importadoras pela qualidade dos suplementos alimentares. É muito importante que os consumidores tenham acesso às informações fidedignas sobre os suplementos proteicos, a fim de assegurar a orientação adequada do consumidor na aquisição de produtos. Estudos futuros serão realizados com um número maior de amostras a fim de verificar se houve uma diminuição das irregularidades na rotulagem. 


\section{REFERÊNCIAS}

ALVES T.O.; MATOS, P. E.; BARBOSA, K. V. S.; CARDOSO, F. T.; SOUZA, G. G. et al. Estimativa do consumo de proteínas e suplementos por praticantes de musculação em uma academia da baixada fluminense, Corpus et Scientia, v.8, n.1, p. 1-10, 2012.

ALVES, C.; LIMA, R. V. B. Uso de suplementos alimentares por adolescentes. Jornal de pediatria, v. 85, n. 4, p. 287-294, 2009. DOI: https://doi.org/10.1590/S0021-75572009000400004

ANDRADE, L. A.; BRAZ, V. G.; NUNES, A. P. O.; VELUTTO, J. N.; MENDES, R. R. Consumo de suplementos alimentares por clientes de uma clínica de nutrição esportiva de São Paulo. Revista Ciência e Movimento, v. 20, n.3, 27-36, 2012. DOI: http://dx.doi.org/10.18511/rbcm.v20i3.3298

BRASIL. Ministério da Saúde. Agência Nacional de Vigilância Sanitária. Resolução RDC $n^{\circ}$ 243, de 26 de julho de 2018. Dispõe Sobre Requisitos Sanitários dos Suplementos Alimentares. Diário Oficial da União, Brasília, 27 de julho de 2018a.

BRASIL. Ministério da Saúde. Agência Nacional de Vigilância Sanitária. Resolução RDC no 18, de 27 de abril de 2010. Aprova o regulamento técnico sobre alimentos para atletas. Diário Oficial da União, Brasília.2010.

BRASIL. Ministério da Saúde. Agência Nacional de Vigilância Sanitária. Instrução Normativa - IN no 28, de 26 de julho de 2018. Estabelece as listas de constituintes, de limites de uso, de alegações e de rotulagem complementar dos suplementos alimentares. Diário Oficial da União, Brasília, 27 de julho de 2018b.

BRASIL. Ministério da Saúde. Agência Nacional de Vigilância Sanitária. Resolução RDC $n^{\circ} 259$, de 20 de setembro de 2002. Regulamento técnico sobre rotulagem de alimentos embalados. Diário Oficial da União, Brasília, 23 de setembro de 2002.

BRASIL. Ministério da Saúde. Agência Nacional de Vigilância Sanitária. Resolução RDC no 429, de 08 de outubro de 2020. Aprova Regulamento Técnico sobre Rotulagem Nutricional de Alimentos Embalados, tornando obrigatória a rotulagem nutricional. Diário Oficial da União, Brasília, 09 de outubro de 2020.

BRASIL. Congresso Nacional. Lei n.10.674, 16 de maio de 2003. Obriga que os produtos alimentícios comercializados informem sobre a presença de glúten. Diário Oficial da República Federativa do Brasil. 2003b.

BRASIL, Ministério da Saúde. Agência Nacional de Vigilância Sanitária. Resolução RDC no 26, 2 de julho de 2015. Dispõe sobre os requisitos para rotulagem obrigatória dos principais alimentos que causam alergias alimentares. Diário Oficial da União, Brasília, 3 de julho de 2015.

CORNISH, L. S.; MORAES, C. The Impact of Consumer Confusion on Nutrition Literacy and Subsequent Dietary Behavior. Psychology and Marketing, v. 32, n. 5, p.558 - 574, 2015. DOI: https://doi.org/10.1002/mar.20800 
CORREARD M.F.P.; ALMEIDA, A. M.; COUTINHO, V. F.; FERRAZ, R. R. N. Uso de suplementos por praticantes de atividade física de uma academia na cidade Pindamonhangaba - SP. Revista UNILUS Ensino e Pesquisa, v. 14, n. 36, p. 265267, 2017. URL: http://revista.unilus.edu.br/index.php/ruep/article/view/894

FISCHBORN, S. C. A.. Influência do Tempo de Ingestão da Suplementação de Whey Protein em Relação à Atividade Física. Revista Brasileira de Nutrição Esportiva. v. $3, \quad$ n. 14, p. 132-143, 2009. URL: http://www.rbne.com.br/index.php/rbne/article/view/109

FRESTEDT, J. L.; ZENK, J. L.; KUSKOWSKI, M. A.; WARD, L. S.; BASTIAN, E. D. A whey-protein supplement increases fat loss and spares lean muscle in obese subjects: a randomized human clinical study. Nutrition \& metabolism, v. 5, n. 1, p. 8, 2008. DOI: $\underline{10.1186 / 1743-7075-5-8}$

FREITAS, H. R.; BIZARELLO, T. B.; ROMANO, U. S.; DA SILVA SANTANA, P. G. B.; DA SILVA, R. H. S. et al. Avaliação da rotulagem e informação nutricional de suplementos proteicos importados no Brasil. RBNE-Revista Brasileira de Nutrição Esportiva, v. 9, n. 49, p. 14-24, $2015 . \quad$ URL: http://www.rbne.com.br/index.php/rbne/article/view/489

FRADE, R. E.; VIEBIG, R. F.; FONSECA, D. C. Avaliação do consumo de suplementos nutricionais por frequentadores de uma academia da cidade de São Paulo-SP. RBNE-Revista Brasileira de Nutrição Esportiva, v.10, n. 55, p. 50-58, 2016. URL: http://www.rbne.com.br/index.php/rbne/article/view/606

HARAGUCHI, F.K.; ABREU, W.C.; PAULA, H. Proteínas do Soro do Leite: Composição, Propriedades Nutricionais, Aplicações no Esporte e Benefícios para a Saúde humana, Revista de Nutrição. v. 19. n. 4, p. 479-488, 2006. URL: https://doi.org/10.1590/S1415-52732006000400007

KRUGER, M. C.; PLIMMER, G. G.; SCHOLLUM, L. M.; HAGGARTY, N.; RAM, S. et al. The effect of whey acidic protein fractions on bone loss in the ovariectomised rat. British Journal of Nutrition, v. 94, n. 2, p. 244-252, 2005. DOI: $\underline{10.1079 / \text { bin20051454 }}$

LISBÔA, C. C. B.; FIAMONCINI, R. L.; NAVARRO, F. Avaliação da adequação da rotulagem nutricional de repositores energéticos comercializados em lojas especializadas em suplementos alimentares de Brasília-DF à legislação vigente. Revista Brasileira de Nutrição Esportiva, v. 5, n. 25, p. 2, 2011. URL: http://www.rbne.com.br/index.php/rbne/article/view/227

LOCKWOOD, C. M.; ROBERTS, M. D.; DALBO, V. J.; SMITH-RYAN, A. E.; KENDALL, K. L. et al. Effects of hydrolyzed whey versus other whey protein supplements on the physiological response to 8 weeks of resistance exercise in college-aged males. Journal of the American College of Nutrition, v. 36, n. 1, p. 16-27, 2017. DOI: 10.1080/07315724.2016.1140094 
LUHOVYY, B. L.; AKHAVAN, T.; ANDERSON, G. H. Whey proteins in the regulation of food intake and satiety. Journal of the American College of Nutrition, v. 26, n. 6, p. 704S-712S, 2007. DOI: 10.1080/07315724.2007.10719651

MACEDO, A.S.; MARTINS, J. V. F.; BARCELLOS, L. T.; TAIRA, L. A.; KHOURI, L. H. M.; et al. O uso de suplementos alimentares por praticantes de atividade física no município de Juiz de Fora - MG e frequência de cálculo renal. Revista Eletrônica Acervo Saúde, v.45, p.1-10, 2020. DOI: https://doi.org/10.25248/reas.e2950.2020

MARETH, B.L. Avaliação da rotulagem dos suplementos energéticos à base de carboidratos comercializados em Brasília. Trabalho de Conclusão de Curso de Graduação em Nutrição. Faculdade de Ciências da Saúde, Universidade de Brasília, Brasília, 2015. URL: https://bdm.unb.br/handle/10483/10773

MOREIRA, S. S. P.; CARDOSO F. T.; SOUZA, G. G.; SILVA, E. B. Avaliação da adequação da rotulagem de suplementos esportivos. Corpus et scientia, v. 9, n. 2, p. $45-55,2013$.

NASCIMENTO, B. P.; ADRIANO, L. S.; CARIOCA, A. A. F.; DOS SANTOS MACHADO, T. J. Adequação da rotulagem de alergênicos em alimentos para atletas. DEMETRA: Alimentação, Nutrição \& Saúde, v. 14, 2019. DOI: https://doi.org/10.12957/demetra.2019.37247

NUERNBERG, A. E.; FIGUEIREDO, T., C., S., B; THOMAZZELLI, F., C., S. Análise dos rótulos de suplementos para atletas comercializados em Blumenau-SC. Revista Brasileira de Nutrição Esportiva, v. 12, n. 72, p. 431-442, 2018. URL: http://www.rbne.com.br/index.php/rbne/article/view/1032

RODRIGUES, M. S.; COSTA JUNIOR, A., L., R. Avaliação da rotulagem de suplementos proteicos comercializados em lojas especializadas em São Luís - MA. RBNE-Revista Brasileira de Nutrição Esportiva, v. 11, n. 64, p. 420-427, 2017. URL: http://www.rbne.com.br/index.php/rbne/article/view/822

SGARBIERI, V. C. Propriedades fisiológicas-funcionais das proteínas do soro de leite. Revista de nutrição, v. 17, n.4.p. 397-409, 2004. DOI: https://doi.org/10.1590/S1415-52732004000400001

SILVA, A. S.; LORENZO, N. D.; SANTOS, O. V. Comparação dos parâmetros de rotulagem e composição nutricional de barras protéicas. Revista Brasileira de Nutrição Esportiva, v. 10. n. 57. p.350-360, 2016. URL: http://www.rbne.com.br/index.php/rbne/article/view/649

SILVA, L. V.; SOUZA, S. V. C. Qualidade de suplementos proteicos: avaliação da composição e rotulagem. Revista do Instituto Adolfo Lutz, v. 75, n. 1703, p. 1-17, 2016. URL: https://pesquisa.bvsalud.org/portal/resource/pt/biblio-982790

SOUZA, L. B. L.; PALMEIRA, M. E.; PALMEIRA, E. O. Eficácia do uso de whey protein associado ao exercício, comparada a outras fontes protéicas sobre a massa muscular de indivíduos jovens e saudáveis. RBNE-Revista Brasileira de Nutrição 
Esportiva, v. $9, \quad$ n. $54, \quad$ p. 607-613, 2015. URL: http://www.rbne.com.br/index.php/rbne/article/view/589

TERADA, L. C.; GODOI, M. R.; SILVA, T. C. V.; MONTEIRO, T. L.I. Efeitos metabólicos da suplementação do Whey protein em praticantes de exercícios com pesos. Revista Brasileira de Nutrição Esportiva, v. 3, n. 16, p. 295-305, 2009. URL: http://www.rbne.com.br/index.php/rbne/article/view/127

TREVIZAN, J. A. C; MANNIGEL, A. R.; BIDO, G. S.; COSTA, A. R.; ANDREOLA, R., FELIPE, D. F. Analysis of the protein content in whey protein dietary supplements. International Journal of Development Research, v. 9, n. 11, pp. 31337-31339, 2019. URL: https://www.journalijdr.com/analysis-protein-content-wheyprotein-dietary-supplements 